DOI: 10.22620/agrisci.2018.23.001

\title{
CHANGES IN BULGARIAN AGRICULTURE AFTER TEN YEARS OF EU MEMBERSHIP
}

\author{
Svetla Yancheva, Christina Yancheva, Petar Borisov*
}

Agricultural University - Plovdiv

*E-mail: peterborisov@gmail.com

\begin{abstract}
The purpose of the article is to identify structural changes in the agricultural sector resulting from the application of the CAP. In the study is used an approach based on PEST-analysis as a tool for identifying changes in the environment in which agriculture is developing. The basic source of data for the analysis is the database collected by the Food and Agriculture Organization (FAO).

The accession to the EU has made a positive impact on the development of Bulgarian agriculture. There is growth in the added gross value generated in the sector, labour productivity and investment. Data analysis shows a real boost of trade with agricultural goods. During the examined period the investment in the sector has grown four times. The share in the total investment in the economy of the country has grown from $2.6 \%$ to $8.9 \%$. Investment costs are incurred for modernization of farms, for environmental protection, upgrading of equipment and for incorporating new technology, training, and acquisition of key competencies for farm management.
\end{abstract}

Keywords: CAP, changes, agriculture, PEST.

\section{INTRODUCTION}

Over the past ten years, Bulgarian agriculture realized necessary changes in the context of the Common Agricultural Policy (CAP). As a full member of the EU, Bulgaria benefits from the advantages of the economic and political union of Europe, but at the same time faces intense competition in the agricultural sector by developed European economies. There is not such a rapid rise in Bulgarian agriculture, and the result is that today European community talks more about the EU's development of "two speeds." Agriculture is one of the industries giving employment of significant share of the EU population.

The sector has a traditional meaning for Bulgarian country as well (Chopeva and Nikolov, 2013). Agriculture is a business, but at the same time and lifestyle, an industry where working conditions are not so attractive, and even in some cases very severe. CAP has great significance to the sustainable development of agriculture in rural areas in all member states (Radev and Radeva, 2017).

The purpose of the article is to present in dynamic the changes in the agricultural sector resulting from the application of the CAP.

\section{Methodology}

In the study, we use PEST-analysis as a tool for identifying changes in the environment for agriculture development. The primary source of data for the analysis is the database collected by
Food and Agriculture Organization (FAO). The examined period 2006-2015 allows to track the dynamics of the studied parameters and to reveal trends in the performance of the agricultural sector.

\section{Changes in the economic environment}

Agriculture bear significant changes that lead to higher efficiency of production and the restructuring of exports and imports. Bulgaria leaves the traditional Russian and Asian markets, and its agrarian products are being traded on the European market.

It is indisputable that after the accession of the country to the $\mathrm{EU}$, there was a steady growth of Gross Value Added (GVA) (Figure 1). In the period 2006-2008 GVA fluctuated. This variation is explained by the ongoing structural changes in the agriculture and mostly determined by the future expectations of investors in the sector who do not have a precise prediction about the way on which will position the Bulgarian agricultural products on the European market.

The time for significant changes in the sector affected by the CAP was about six years. During this period we observed the sharpest fluctuations in GVA, which proves that without government intervention in the sector, it cannot sustain the new market conditions. The government intervention in agricultural sector gradually decreases and reached its minimum of 0.5 billion USD during 2010. 
There was a sharp increase in GVA, in the sector in 2012, and GVA reached its peak of over 3.5 billion USA in 2015. One of the reasons was the increased support from the government that reaches nearly 1 billion USD in 2015. The two curves of studied indicators show a positive correlation between the increase in GVA and increase of government payments (Fig. 1). The curve of GVA is positioned above the curve of the state support, indicating that the government payments have a multiplier effect and lead to a positive development of agriculture in the period 2012-2015.

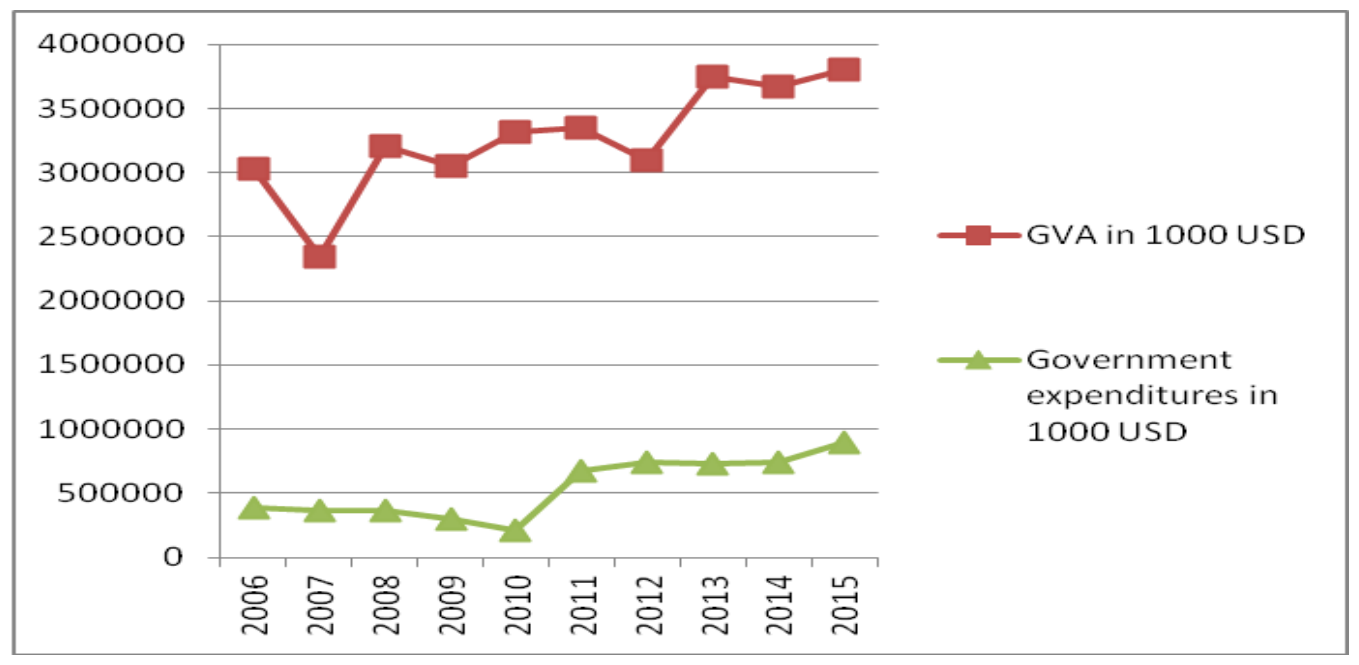

Fig. 1. GVA and Government expenditures 2006-2015 (in thousand USD)

Source: FAO. www.fao.org

Agriculture generated just over $6 \%$ of the country's gross domestic product (GDP) in 2006 and until 2009 GDP fluctuated due to the ongoing structural changes in the sector (Fig. 2). After Bulgaria joined the EU, the curve of GDP calm down and follow the EU's curve. The development of the sector, affected by the CAP become more balanced. Overall, the rate which generates the sector significantly reduced and in 2015 reached a level of $4.4 \%$. Meanwhile, the country's GDP in the same period was increasing, giving reason to conclude that agriculture is becoming not so essential for the development of Bulgarian economy.

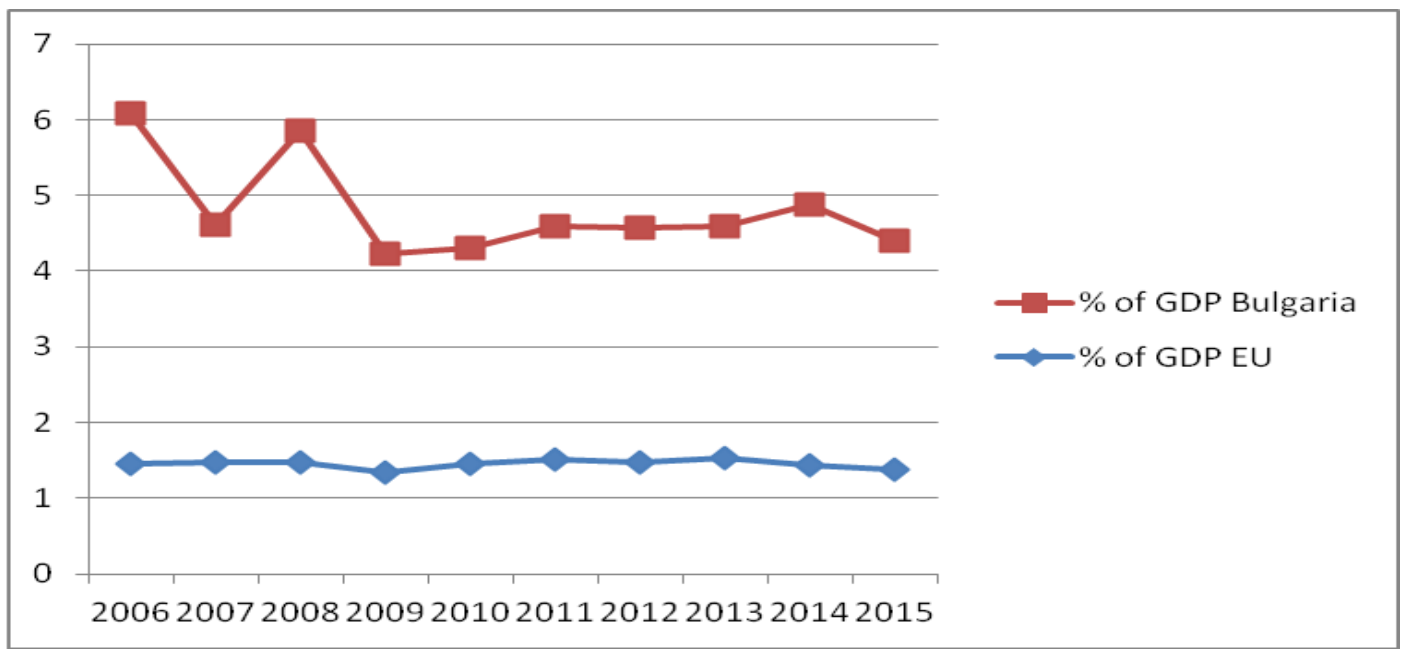

Fig. 2. Share of agriculture in GDP compare to EU level (\%)

Source: FAO.www.fao.org 
As a new member state of the EU, Bulgaria becomes an attractive destination for investment, including and the agrarian sector (Fig. 3). At the beginning of the period, foreign direct investment (FDI) in the sector increased nearly 3 times - from 35 million USD in 2007 to more than 100 million USD in 2008. In 2008, the global economy was affected by the financial crisis, leading to a rapid outflow of investments in Bulgarian agriculture, and FDI collapsed to 5.3 million USD, only two years after the realized boom. There was a slight recovery in the investment activity in the sector, but it was sluggish, and the reached peak in 2008 has never again repeated.

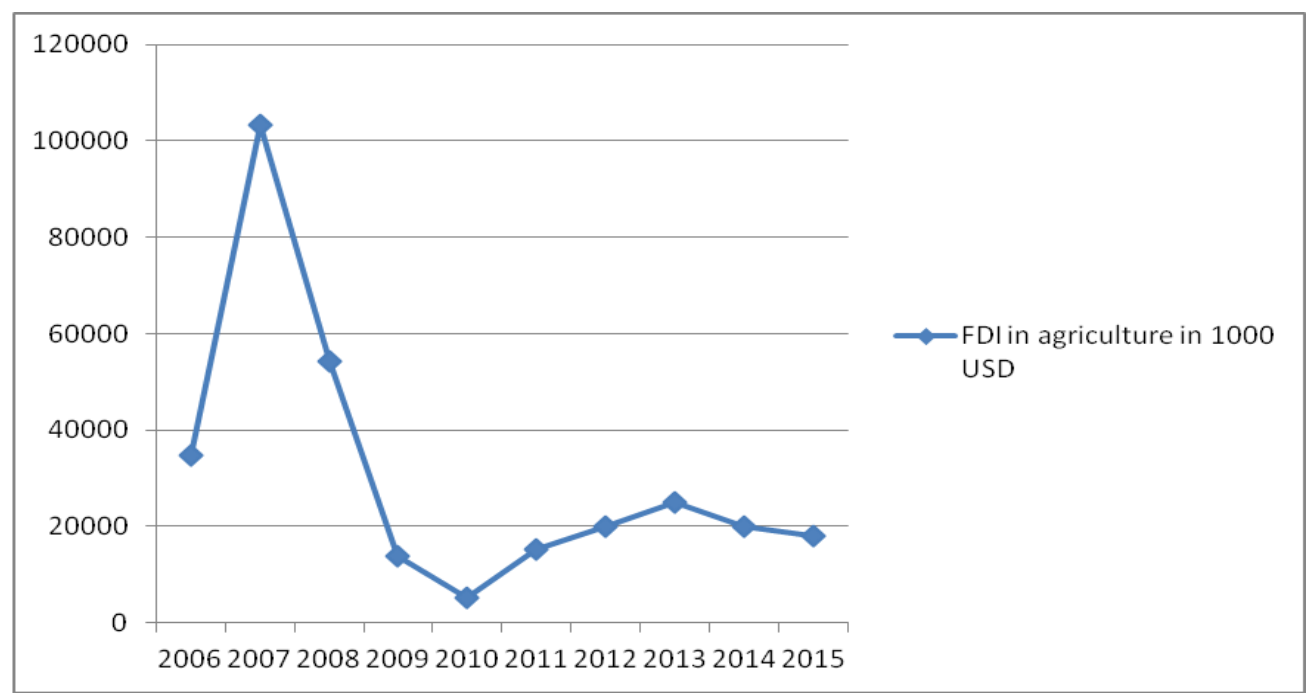

Fig. 3. FDI in Bulgarian agriculture 2006-2015 (thousand USD)

Source: FAO.www.fao.org

Agriculture is a risky sector and not so attractive for lending by credit organizations. However, in the period 2006-2015 the loans in the sector increased almost four times and reached over 1 billion USD. The support from the lending organizations is almost equal to that, which comes from the government. There is a sharp increase in credit in the sector in 2008 - over 0.8 billion USD. Apparently, the confidence in the favorable development of agriculture by creditors is high, because Bulgaria now has full access to the EU market. Between 2010 and 2014, there is a boom in lending to the sector, and loans reached more than 1 billion USD in 2014. The lending boom is determined by the investment costs that farmers do, motivated by the subsidized payments from the EU and the Bulgarian government.

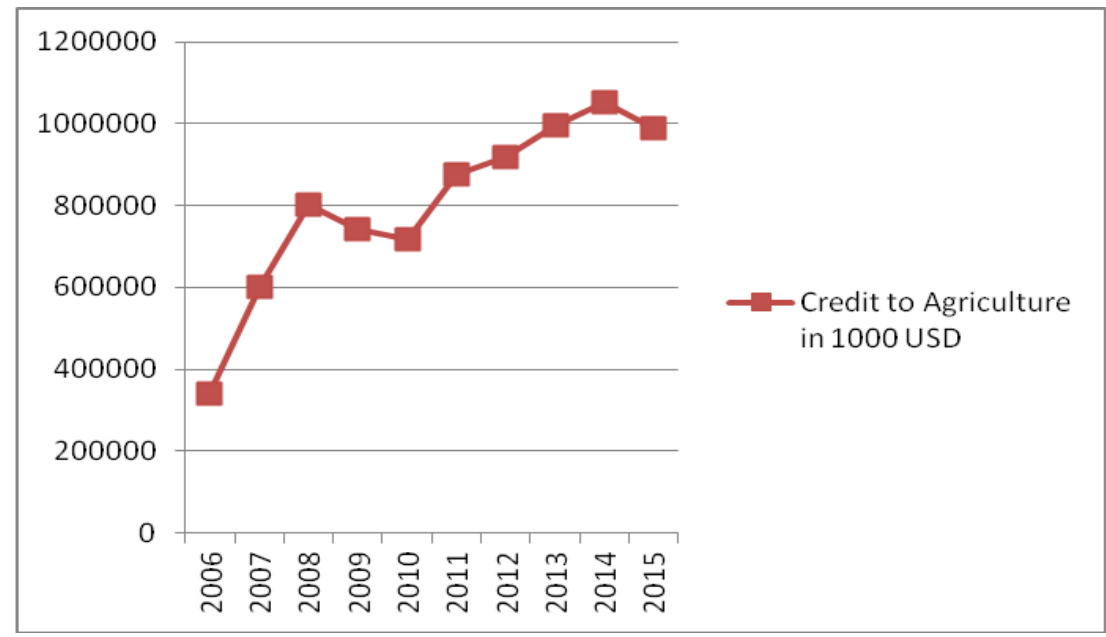

Fig. 4. Credit to Agriculture in 1000 USD 
CAP strongly influenced the Bulgarian agriculture (Fig. 5). Agricultural production grew from 3 to almost 4 billion USD in the period 20062015. The import of agricultural products, follow the same trend and increased from 1.2 billion USD in 2006 to 2.8 billion USD in 2008. There was a slight decline in the period 2008-2010, explained by the re-orientation of imports, as the leading importers of agricultural products become the EU member states. Data presented in Fig. 5 show that export was rapidly increased during the studied period. In 2008 exports increased significantly and reached 2.9 billion USD, the next significant increase was in 2011 and the last one in 2014. In 2015 exports is 5.3 billion USD, which is 1.5 times increase for the last 10 years. Interestingly, the years with a dramatic increase in lending to the sector coincide with the years, in which there was a dramatic increase in exports. There is a correlation between credit boom in the sector and the boom in exports of agricultural products. Bulgaria exports more products than the produced ones in the last 10 years, explained by the fact that most of the imports of agricultural products in the country were exported by adding value. The trade balance was negative in 2007, but it lasted for a short period, and in 2008 the trade balance was rising and turned to a positive value. Due to the high export growth, which exceeded the import growth, the trade balance in the sector was rising and in 2015 reached 2 billion USD.

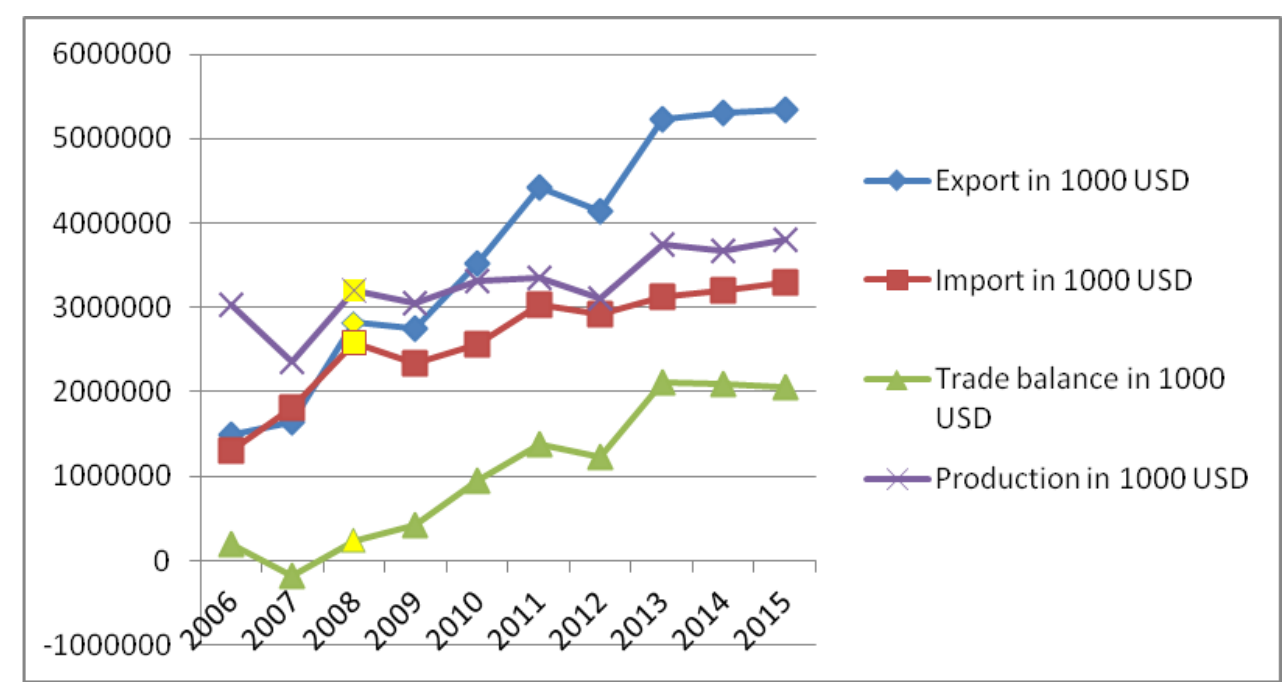

Fig. 5. Production, Export, Import, and Trade balance in 1000 USD

Source: FAO.www.fao.org

\section{Changes in the social environment}

The development of the social factor was determined by the economic potential of the region. Agriculture is not only a business but also a way of life in rural areas. In these regions of the country, agriculture is the main livelihood for the population. That is why agriculture plays a significant role in the socio-economic development of rural areas in Bulgaria.

During the last 10 years, the rural population decreased from 2.2 million people in 2006 to 1.8 million people in 2015 (Fig. 6). The graph shows the tendency of depopulation of rural areas in Bulgaria. At the same time, employment in the agricultural sector does not fluctuate significantly, leading to the conclusion that this sector has strengthened its role as a backbone for rural economic development. Farmers expressed as a percentage of the population living in rural areas are too low. According to data (see Fig. 7) $12 \%$ of the rural population is engaged in agriculture in 2006.

This rate is gradually decreasing and returning to the same level in 2008. An interesting fact is that after the accession of Bulgaria to the EU and its incorporation to the CAP the percentage of people employed in agriculture in rural areas began to vary. In the period 2008-2013, the percentage of the employed in agriculture reaches $10 \%$, after that follows recovery and this share reaches $11.5 \%$ in 2016.

All these data suggest that CAP in rural areas appears as a powerful tool to stimulate employment. The Program for Rural Development, through its measures, plays the role of a typical buffer in the fight against poverty. The rural population employed in the agriculture sector operates mainly in small-sized farms. 
According to Ministry of Agriculture, Forests and Food identified in the report (Agricultural Census in Bulgaria in 2010 - Results - 2012) $85 \%$ of farms are small-sized, and they constitute a significant source of income for their owners. Subsidizing these farms determines the annual employment rate in rural areas. The significant share of the subsidy goes to those farms to expand their production and modernization, which immediately reflects on the number of employed seasonal workers in agriculture. The CAP mechanisms are guaranteeing employment in rural areas. However, for the last 10 years, rural areas have been depopulated at a rapid speed. What the state was able to do that through the CAP achieves sustainable employment over the years in rural areas.

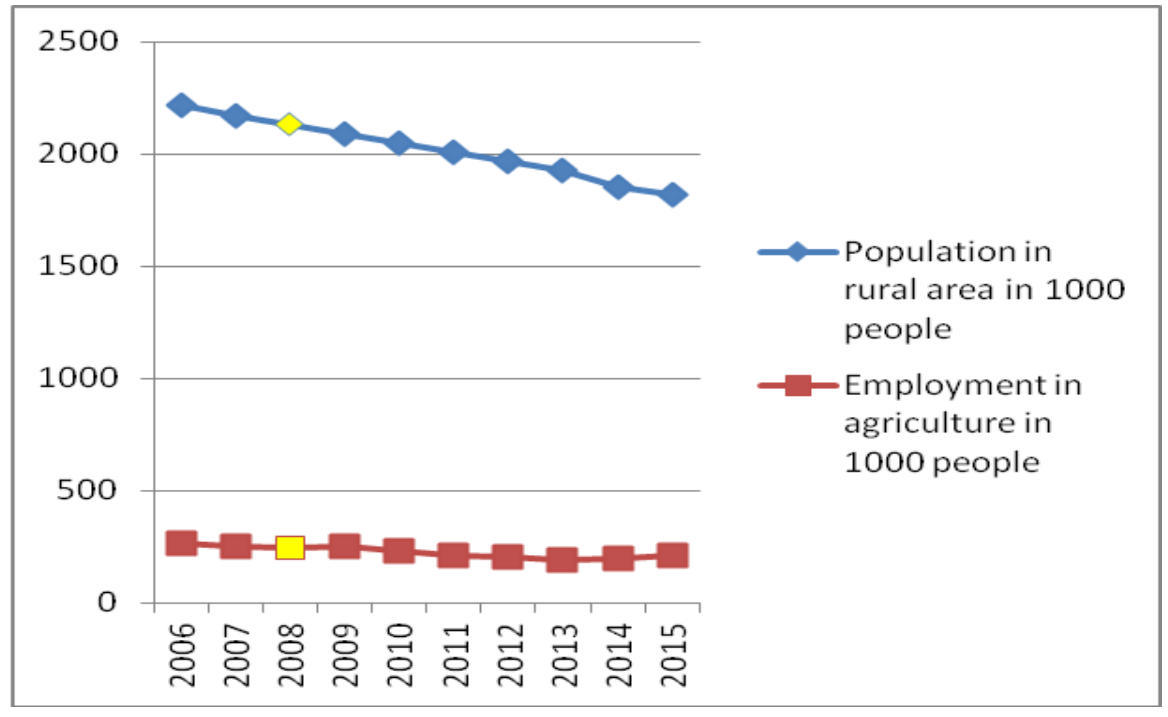

Fig. 6. Population in rural areas and employment in agriculture

Source: FAO.wWw.fao.org

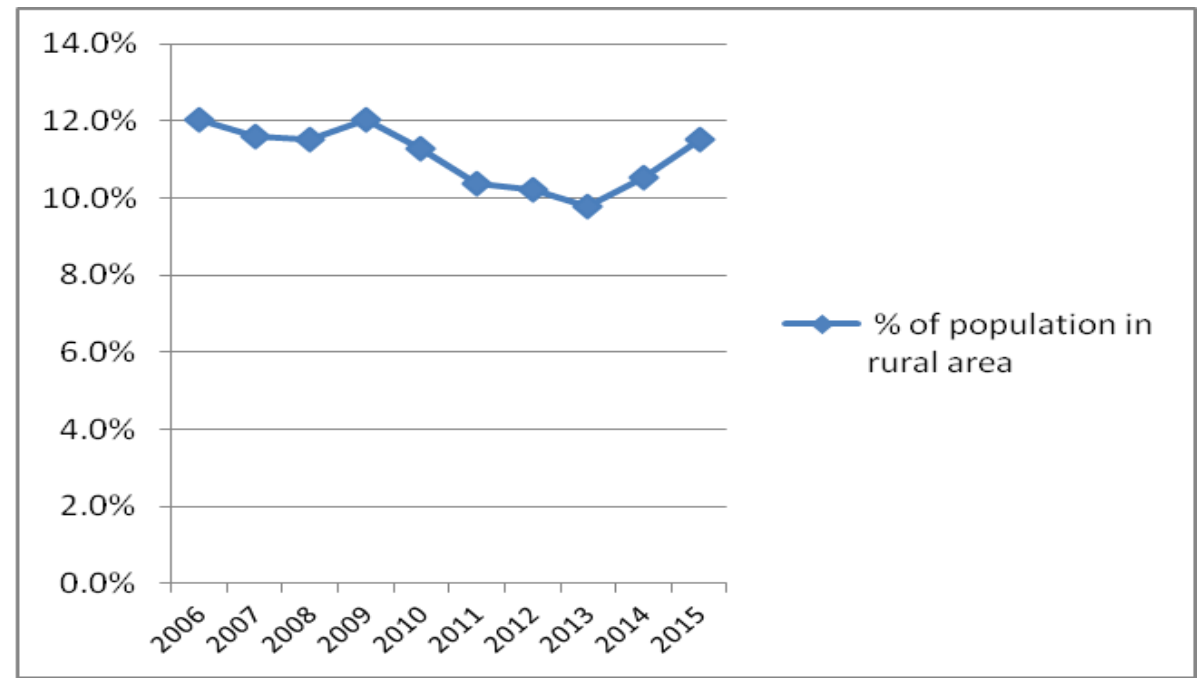

Fig. 7. Share of people living in rural area

\section{Source: FAO.wWw.fao.org}

\section{Changes in ecological environment}

Agriculture is heavily dependent on the availability of natural resources, and it is in close interaction with the ecology of the region. As a sector that uses natural resources that are unrecoverable, it is one of the leading pollutants. Financial support for agriculture leads to an intensification of production which, despite the boom of innovative technologies in the sector, increases the levels of pollution in rural areas. 
Over the last 10 years, Bulgaria has increased emissions of carbon dioxide as a result of the intensification of agriculture. Undisputed is the fact that the CAP supports farms and rural development while respecting environmental principles. However, intensification leads to higher and higher levels of contamination (see Fig. 8). The data shows that after 2008 carbon dioxide emissions are increased by sustainable growth.

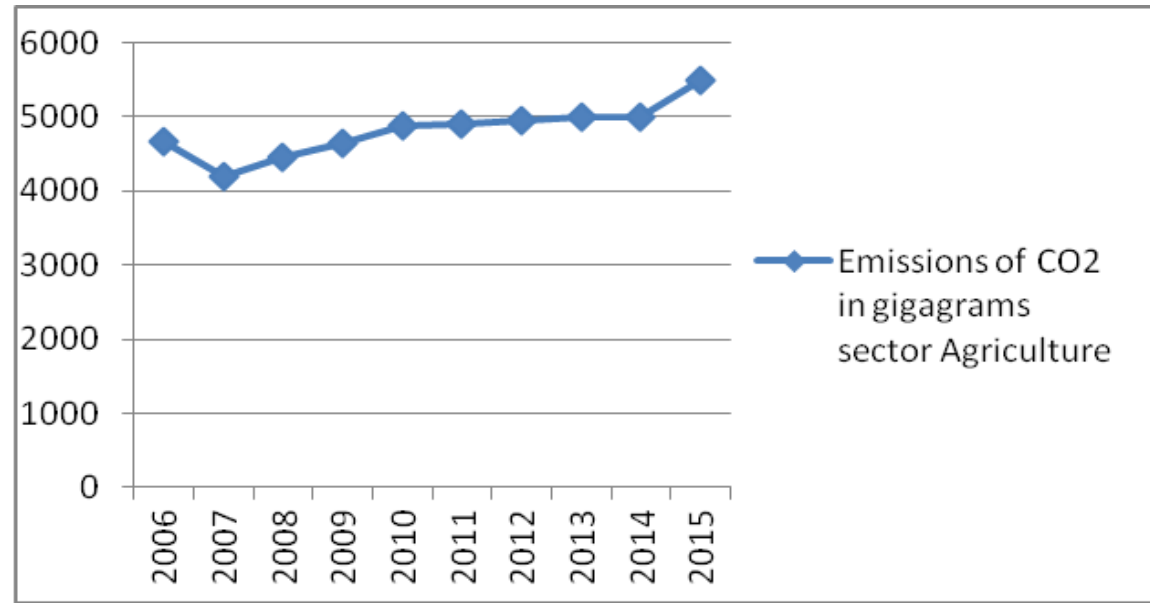

\section{Source: FAO. www.fao.org}

The inclusion in the economic turnover of more farmland is a fact - farmland has increased by $10 \%$ (Fig. 10). This increase is at the expense of the near $10 \%$ reduction in the meadows and pastures in the country. Intensification of production leads to an increase in the arable land by plowing more pastures, thus losing biodiversity and threatens the ecological balance. Pesticides and fertilizers are another critical factors in the intensification of the farms. In recent years, fertilizer levels have increased significantly. In 2006 the average rate of implicated fertilizers in Bulgarian agriculture was 22,5 kg/ha, while in 2015 the implicated fertilizers reach $44 \mathrm{~kg} / \mathrm{ha}$. The presented data shows that this process is gaining momentum (see Fig. 9). In 2011 and 2013, there is a critical increase of used fertilizers in Bulgarian agriculture. The leading consumer of fertilizers is the grain sector. This sector influenced by the CAP is being developed and modernized at a fast pace. Grain production is the main player, responsible for reducing pastures and increasing the fertilization levels in agriculture. Achieving higher productivity of the crops is at the cost of using more fertilizer and arable land. Pesticides are another major pollutant of the environment. Pesticide use, remaining at low levels and has a permanently supplied character over the years (see Fig. 9).

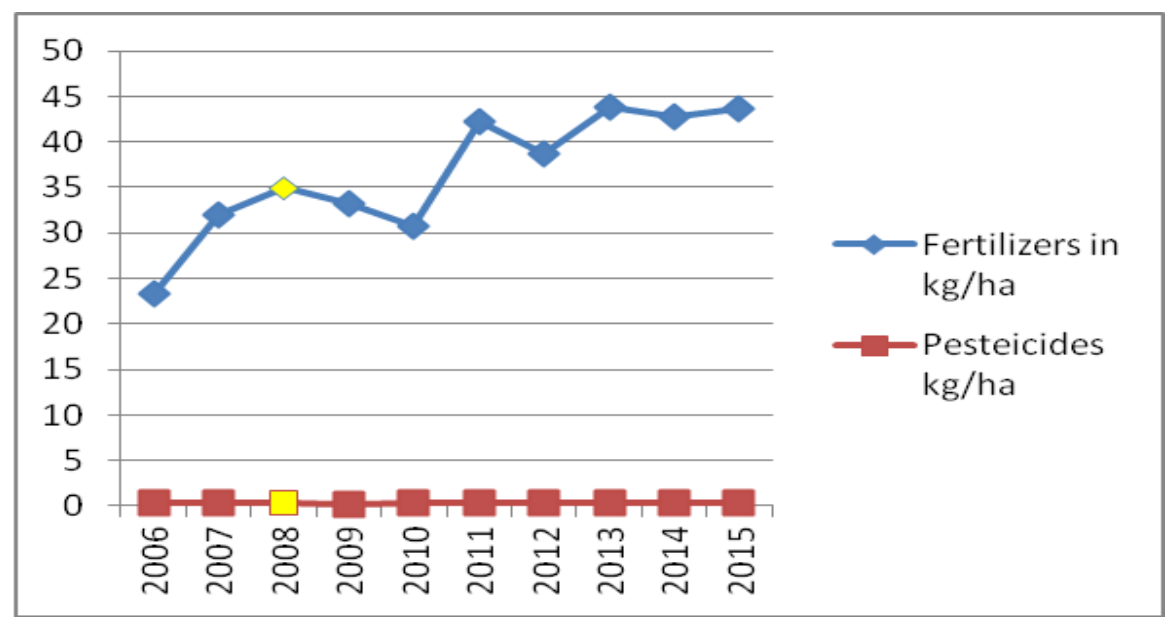

Fig. 9. Usage of fertilizers and pesticides in Agriculture 


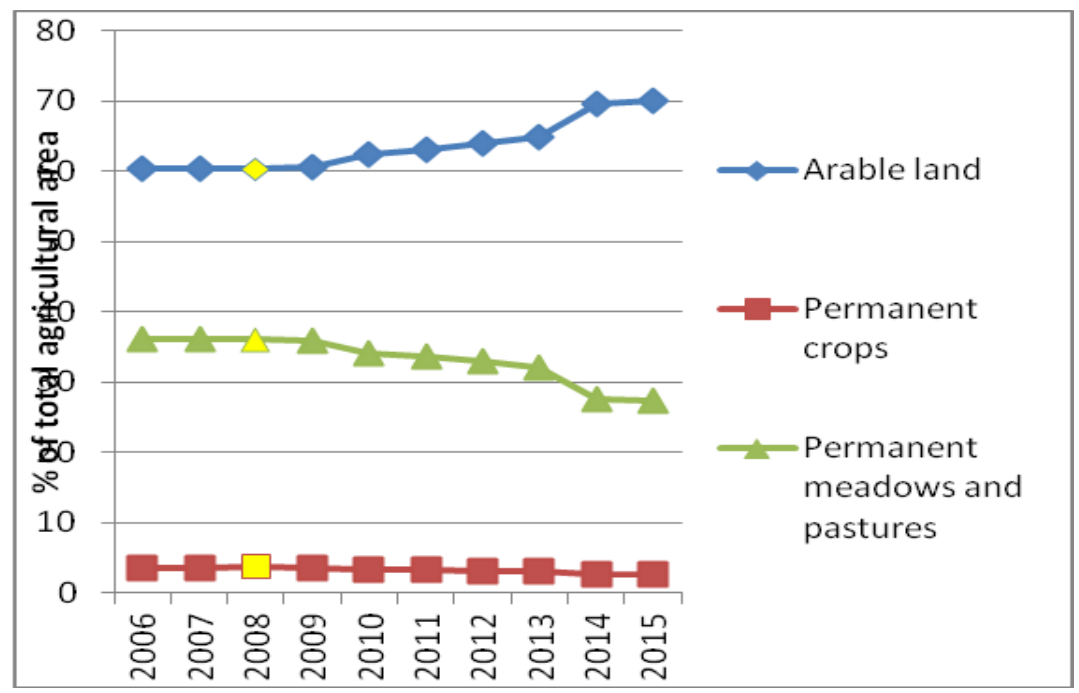

Source: FAO.www.fao.org

Fig. 10. Structure of agricultural land

Water is another natural resource that is essential for the development of agriculture in rural areas. The long period of transition lead to the destruction of irrigation infrastructure in agriculture. Bulgarian agriculture specializes in the production of grain, which does not require the availability of irrigation systems. The use of water for agricultural purposes decreased over the last ten years (see Fig. 11). In 2006, nearly $17 \%$ of the state's water resources available went to irrigation, while in 2015 it is already $15.2 \%$. An alternative approach to saving water resources is the use of new technologies such as drip or sprinkler irrigation to achieve maximum effect in the crop on a minimum cost of water.
Most of the farms, specialized in fruit and vegetable production benefit from resource-saving irrigation technologies thanks to subsidies. Under the influence of the CAP, many municipalities in the rural areas have been able to build and modernize their water treatment plants and irrigation infrastructure, thus contributing to the conservation of water resources. The alarming fact remains that small farms can not allocate financial resources for the purchase of modern irrigation systems, and they secure their water resources by drilling or using well water. These practices lead to waterlessness in areas characterized by seasonal drought.

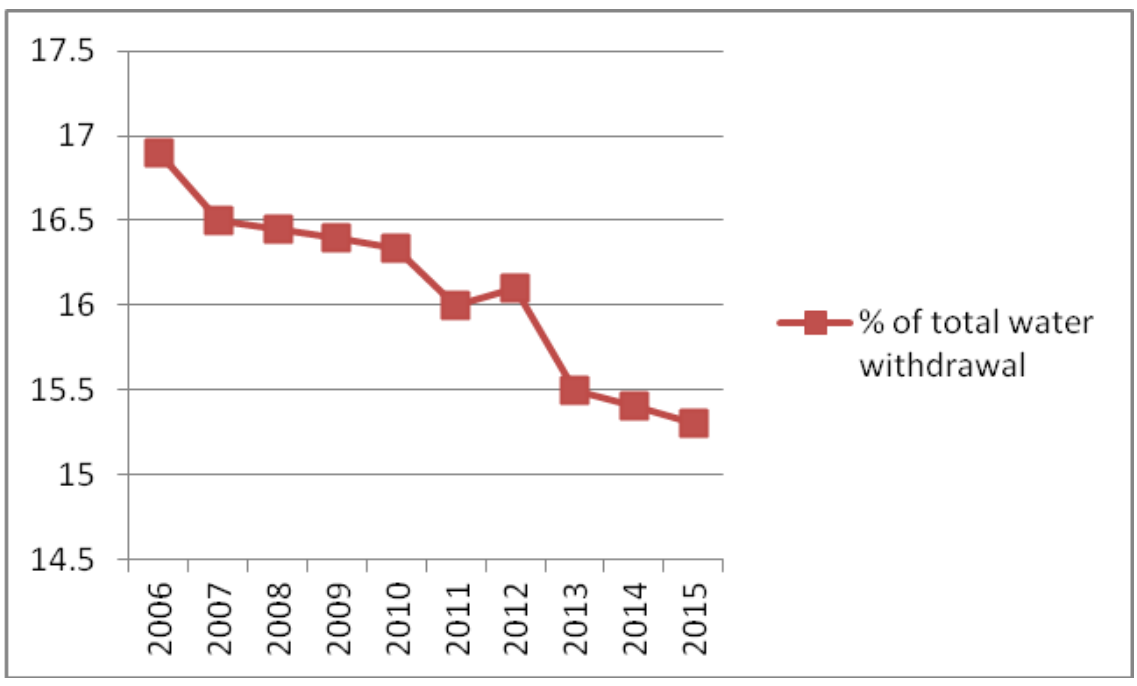

Fig. 11. Usage of water in Agriculture 


\section{Changes in the political environment}

Agriculture is not only an industry generating food, but in most cases, the only way of subsistence in rural areas of Bulgaria. That is why the sector has a strategic importance for the development of economy and society. In this sense, the government policy to promote the development of agriculture is vital for the rural areas and to ensure stable food supply at market prices, giving access to everyone on the food market. Due to the governmental support and CAP, Bulgarian agriculture has financial resources necessary for its development. Provided financial resources are not sufficient conditions for the development of agriculture, it is necessary to ensure access to it for every farmer who works in the real sector.

Over the past 10 years, there was a bipolar structure of agricultural farms, namely a small number of large-sized farms processing the majority of agricultural land and many small-sized farms, using a small share of agricultural land. Such duopoly was a prerequisite for the unbalanced spending of financial resources for the development of agriculture.
Large-scale farms have better market positions and access to subsidies than small ones, leading to unequal distribution of financial resources and sharpening the sense of injustice among small farmers. This feeling of injustice reflected the perception of corruption in the country (Fig. 12). Corruption Perceptions Index (CPI) measuring the perceptions of levels of corruption in the state fluctuates between 4 and 4.1 points in the period 2006-2007, which positioned Bulgaria at 59th place among the 149 countries surveyed around the world.

Once at the joining of Bulgaria to the EU in 2008, CPI fell significantly in value, indicating a high distrust of the public. The society is very concern how the state manages the funds and about the manner of distribution of wealth. In the period 2008-2012 the lowest level of the index was achieved, indicating a high distrust of the society according to the applied state policy. In $2013 \mathrm{CPI}$ begins to grow, reaching the level of 2006 and to 2016 it has stabilized, indicating increasing public confidence and the availability of feeling for corruption reducing.

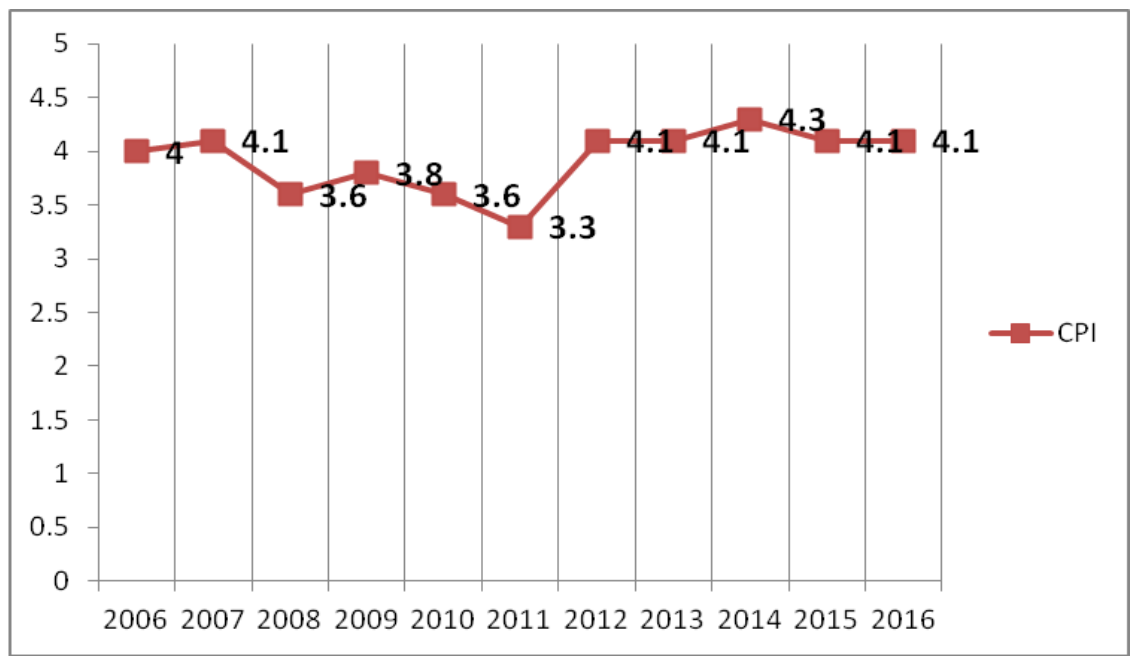

Fig. 12. Corruption Perceptions Index (CPI) in Bulgaria

Source: www.transperancy.bg

Last decade Bulgaria made significant changes to the manner of supporting agriculture. The governmental structure regulating the sector is the Ministry of Agriculture, Forestry and Food (MAF), providing funding, advisory services and research and development products (Fig. 13). Financing of agriculture is carried out by the National Paying Agency, which has 28 branches performing payments to farmers applying for financial aid. State Fund Agriculture (SFA) - Paying
Agency (PA) established in 1998 under the Agricultural Producers Support Act. It provides financial support to farmers under state aid programmes, pre-accession program SAPARD, Common Agricultural Policy (CAP) and Common Fisheries Policy (CFP) of the European Union, including both pillars: Direct payments and Rural Development Programme. The European Commission accredits the SFA as Paying Agency (PA). 
Through the 28 regional directorates "Agriculture," all around the country, and the 27 regional branches of the National Agricultural Advisory, MAF ensures advisory for farmers and collect statistical data needed for planning the sustainability of farms and rural areas.
MAF seeks to promote the technological transfer of knowledge in the agriculture through the structures of the Agricultural Academy, including 25 research institutes that develop scientific products ready for use in agriculture.

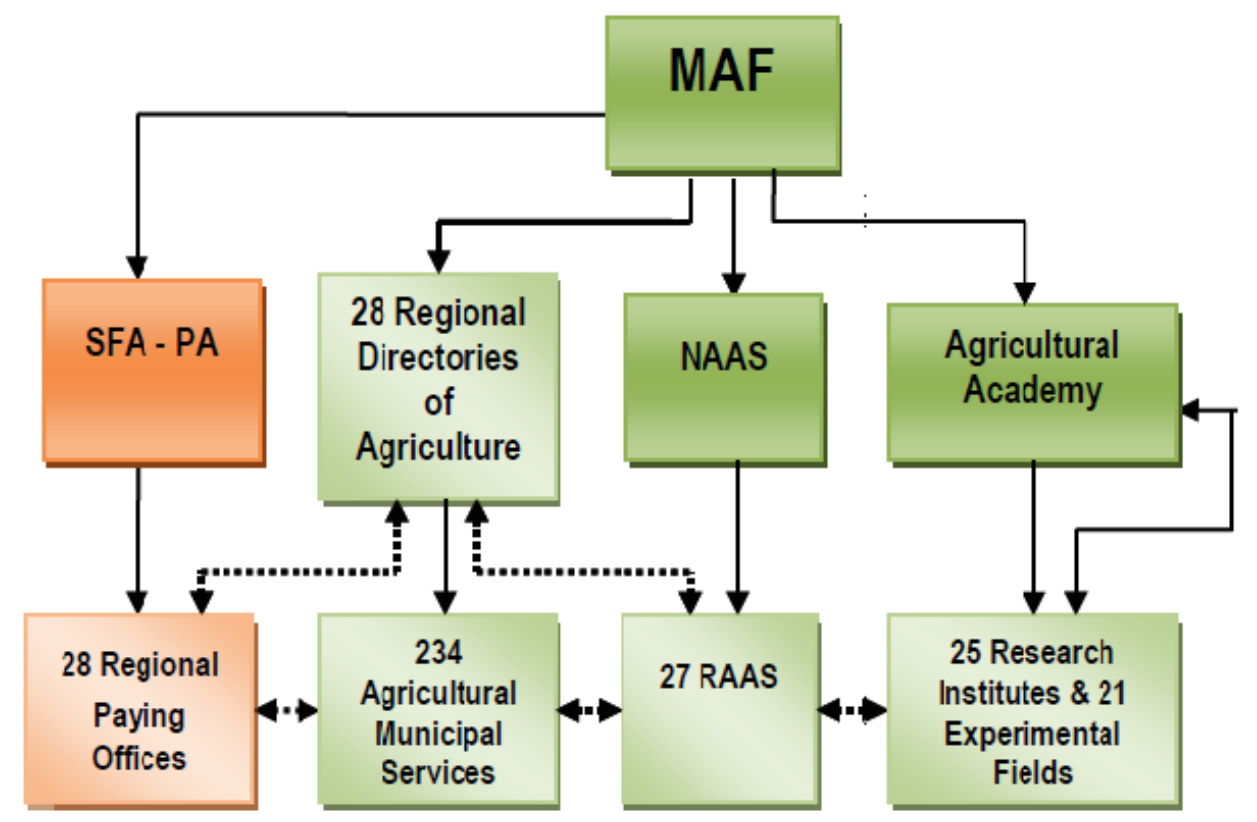

Fig. 13. Governmental mechanism in Bulgarian agriculture

Source: Dirimanova, V. AKIS and advisory services in Bulgaria. PRO-AKIS project report, 2016

The primary instrument for supporting farmers and rural development is the Rural Development Program. The National Paying Agency finances and controls the spending of the funds provided in the Rural Development Program (RDP). The RDP for the period 2007-2013 has spent 2.9 billion USD and for the next RDP 20142020 are allocated another 0.8 billion USD to help farmers. Under the RDP 2007-2013, 98.91\% of the planned budget has been realized.

Thanks to the National Agricultural Advisory Service (NAAS), which conducts numerous information campaigns and prepares grants for farmers for financial assistance, the financial resource is efficiently utilized.

\section{CONCLUSION}

Accession to the EU has made a positive impact on the development of Bulgarian agriculture. There is growth in gross value added generated in the sector, labor productivity and investments. There is a real boost of trade with agricultural goods. During the examined period the investment in the sector grew nearly 4 times. Their share in total investment in the economy of the country increased from $2.6 \%$ to $8.9 \%$. Investment costs have incurred for modernization of farms, for environmental protection, upgrading of the equipment and for incorporating new technologies, for training, and acquisition of key competencies for farm management.

After accession to the EU Bulgarian export of agricultural products has shown a trend of growth. From just over 1 billion USD in 2006, for 10 years agricultural exports increased nearly 4 times, and foreign trade balance following a trend of steady growth. There is a gradual redirection of exports to EU countries at the expense of those outside the Union - the EU currently forms $75 \%$ of the agricultural trade of the country.

Factor for these positive results are the ongoing processes of consolidation and modernization of production structures that lead to increased efficiency and competitiveness of Bulgarian agriculture. 
In the sector, run intensive restructuring changes and consolidation of production factors. There is a tendency to permanently reduce the number of farms, mainly at the expense of small, non-market structures that produce for their own needs. Since the accession of Bulgaria to the EU until now, the number of farms decreased over 3 times. Meanwhile, in Bulgarian agriculture, there is running process of concentration of land in the hands of holders of most extensive farms, and to the current moment, they manage $83 \%$ of it.

The average size of agricultural land in farms increased from 4,4 ha to 15,2 ha for the past ten years. There is a growing interest in the population to do business in agriculture, which results in decreased uncultivated lands nearly 3 times. Intensification of agriculture is carried out taking into account the increased use of pesticides, fertilizers, and water, as factors necessary for the process. Intensification leads to adverse effects, which is further enhanced by national and EU financial support to the sector.

A specific feature of the structure of farms in Bulgaria is its dual nature. It is expressed in a large number of small-sized farms, processing a small part of the utilized agricultural area, and a small number of large-sized farms, processing a significant part of the agricultural land. Small-sized farms are of a particular importance regarding employing in rural areas and act as a standard buffer in the fight against the poverty. Despite the efforts of the government to destroy this bipolarity, there is still a tiny group of medium-sized farms, whose role is to be sustainable and economically viable structures in rural areas, ensuring the reduction of the flow of people to urban areas and abroad.

\section{REFERENCES}

Borisov, P., T. Radev, D. Nikolov, 2014. Analysis of the strategic factors for the development of small agricultural farms in Bulgaria, Economics and Management of Agriculture, № 2.

Chopeva, M., D. Nikolov, 2014. Evaluation of Economic Diversification and Risk on Farms in Bulgaria. Ikonomika i upravlenie na selskoto stopanstvo 2/2014, Sofia.

Dirimanova, V. AKIS and advisory services in Bulgaria. PRO-AKIS project report, 2016.

Radev, T., T. Radeva, 2017. Development of Bulgarian agriculture under conditions of common agricultural policy of European Union. International conference IAE. Polish and Bulgarian Agriculture and Rural Areas in the Common Agricultural Policy. September 12-13, 2017, Sofia.

MAF, 2010. Preliminary Data Census for Bulgarian farmers for 2010, published by MAF.

MAF, 2013. Agriculture in Bulgaria, published by MAF, 2013.

NAAS, 2012. Annual report of the NAAS, published by NAAS.

NAAS, 2011. Annual report of the NAAS, published by NAAS.

National Rural Development Programme (20072013) for Bulgaria.

Statistical database of FAO.www.fao.org 